\title{
O vocativo nas formas de tratamento: análise de fragmentos do romance $M e u$ destino é pecar, de Nelson Rodrigues
}

\section{The vocative in address forms: analysis of fragments of Meu destino é pecar, by Nelson Rodrigues}

\author{
Fabiana Meireles de Oliveira ${ }^{*}$ \\ Universidade de São Paulo \\ São Paulo, São Paulo, Brasil \\ Yedda Alves de Oliveira Caggiano Blanco** \\ Universidade de São Paulo \\ São Paulo, São Paulo, Brasil \\ Luiz Antônio da Silva*** \\ Universidade de São Paulo \\ São Paulo, São Paulo, Brasil
}

\begin{abstract}
Resumo: O objetivo deste artigo é analisar, especificamente, de que maneira o vocativo pode ser entendido como forma de tratamento, dentre os seus diversos níveis - formas pronominalizadas, nominais, vocativas e referenciais - ou, conforme propõe Silva (2008), como um indicador da dêixis social e como atividade estratégica de (des)cortesia comunicativa. Nesse sentido, entendemos que o vocativo, normalmente, na gramática, é tido como um termo que interpela ou chama o interlocutor, que se encontra separado da oração, ao passo que, na pragmática, os interactantes podem utilizá-lo na interação como forma de tratamento, ganhando uma dimensão contextual mais complexa e dinâmica no que se refere ao uso da linguagem, e também para expressar (des)cortesia verbal. Para a análise das formas vocativas (também chamadas de fórmulas apelativas), utilizamos fragmentos do romance Meu destino é pecar, de Nelson Rodrigues. A importância deste estudo se explica na medida em que o vocativo como forma de tratamento é uma atividade argumentativoestratégica que excede as explicações de simetria e poder relativo (BROWN; LEVINSON, 1987[1978]), e das prescrições do socialmente convencionalizado. Assim, veremos que as relações de solidariedade e poder, como postulam Brown e Gilman (1960), nem sempre são as que determinam as formas de tratamento nas interações sociais. Finalmente, consideramos que as formas de tratamento expressam de modo significativo as relações sociais, e que tais atividades só podem ser compreendidas e abordadas contextualmente, interação a interação, conforme as finalidades estratégico-pragmáticas dos interactantes.
\end{abstract}

Palavras-chave: Formas de tratamento. Vocativo. Interação. Estratégia.

*Doutoranda do Programa de Pós-Graduação em Filologia e Língua Portuguesa - PPGFLP - Universidade de São Paulo, São Paulo, São Paulo, Brasil. E-mail: fabi.meireles@hotmail.com.

**Doutoranda do Programa de Pós-Graduação em Filologia e Língua Portuguesa - PPGFLP - Universidade de São Paulo, São Paulo, São Paulo, Brasil. E-mail: yeddablanco@usp.br.

***Professor do Programa de Pós-Graduação em Filologia e Língua Portuguesa - PPGFLP - Universidade de São Paulo, São Paulo, São Paulo, Brasil. E-mail: luizs@usp.br. 


\begin{abstract}
The objective of this paper is to analyze specifically how the vocative can be understood as address forms among its several levels - pronominalized, nominal, vocative and referential forms - or, as proposed by Silva (2008), as an indicator of social deixis and as a strategic activity of communicative (dis)courtesy. In this sense, we understand that vocative, usually in grammar, is taken as a term that interpellates or calls the interlocutor, who is separated from the sentence, whereas, in pragmatics, interactants can use it in interaction as a form of address, gaining a more complex and dynamic contextual dimension regarding the use of language, and also to express verbal (im)politeness. For the analysis of the vocative forms (also called appealing formulas), we use fragments of the novel Meu destino épecar, by Nelson Rodrigues. The importance of this study is explained for the vocative is a form of address as an argumentative-strategic activity that exceeds the explanations of symmetry and relative power (BROWN; LEVINSON, 1987[1978]), and the prescriptions of the socially conventionalized. Thus, we will see that relations of solidarity and power, as Brown and Gilman (1960) postulate, are not always the ones that determine the forms of address.in social interactions. Finally, we consider that the forms of address express significant social relations, and that such activities can only be understood and approached contextually, interaction to interaction, according to the strategic-pragmatic aims of the interacting.
\end{abstract}

Keywords: Forms of treatment. Vocative. Interaction. Strategy.

\title{
1 INTRODUÇÃO
}

As formas de tratamento, segundo Preti (1984), podem revelar solidariedade, intimidade, afetividade, reverência, hierarquia e poder, dependendo do papel e das finalidades específicas estabelecidas na interação entre os participantes no processo comunicativo. Seu uso é estratégico de acordo com a intenção do locutor, indo além do estabelecido pelas formas gramatical e socialmente convencionalizadas. Além dos efeitos eufemísticos e disfemísticos que certos vocativos contêm, cremos que eles, enquanto formas de tratamento, podem ser empregados como mais uma tática argumentativodiscursiva para atingir os fins do falante na interação: aproximar ou afastar socialmente o interlocutor, independentemente de seu valor convencional.

Diante do exposto, o objetivo deste estudo é mostrar que formas de tratamento consideradas prototipicamente corteses -aquelas que mantêm o equilíbrio das imagens dos interactantes na interação- podem ser empregadas com finalidade descortês.

Para o trabalho, na fundamentação teórica, iremos utilizar os fundamentos sobre cortesia, de Diana Bravo et al. (1999) e Briz (2003); descortesia, de Culpeper $(2005,2011)$ e Kaul de Marlageon (2005); anticortesia, de Zimmermann (2005) e, sobre formas de Tratamento, de Silva (2008). O corpus a ser analisado é constituído de fragmentos retirados da obra Meu destino é pecar, de Nelson Rodrigues.

\section{FORMAS DE TRATAMENTO E FUNÇÕES}

Entendemos por formas de tratamento o modo como nos dirigimos ao outro, isto é, como que nos referenciamos ao outro interlocutor num processo de interação conversacional ou escrita. $\mathrm{O}$ uso da escolha da forma adequada a cada situação faz as formas de tratamento estarem relacionadas a aspectos de hierarquia social, vínculo entre os interlocutores, padrões de uso da linguagem etc. 
Diante disso, Preti (2004, p. 184-185) explica como as formas de tratamento podem ser representadas:

Em português, o sistema de tratamento pode ser representado:1) por formas pronominais, ou seja pelos pronomes pessoais (tu, vós); 2) por formas pronominalizadas, isto é, com valor de pronomes pessoais (você, o senhor, vossa excelência, vossa senhoria e suas variações); 3)por formas nominais constituídas por nomes próprios, prenomes, nomes de parentesco ou equivalentes, antecedidos de artigo, uso praticamente restrito ao português de Portugal ou, ainda, por uma grande variedade de nomes empregados como vocativos ou formas de chamamento.

E Silva (2008) as definiu como "palavras ou sintagmas que o usuário da língua emprega para se dirigir e/ou se referir a outra pessoa".

Salienta-se que o uso de algumas formas de tratamento está relacionado ao status e ao papel social que o indivíduo desempenha nas diferentes situações comunicativas, tendo também o objetivo de preservar a autoimagem ou a imagem social do interlocutor. Alguns usos podem se consolidar por um tempo maior, enquanto outros se perdem rapidamente em consequência das transformações sociais e culturais.

Assim, as formas excedem o meramente gramatical e devem ser compreendidas dentro do contexto situacional da língua.

\subsection{FUNÇÕES DAS FORMAS DE TRATAMENTO}

As formas de tratamento fazem parte das regras que regulam o comportamento dos indivíduos nas diversas circunstâncias interativas, que podem se apresentar como adequadas ou não adequadas. Nesse sentido, o êxito da comunicação dependerá da seleção de formas linguísticas apropriadas a cada situação enunciativa dos interlocutores.

Assim, as formas de tratamento possuem as seguintes funções:

a) função de dêitico social (estratificação social, poder relativo dos interlocutores, idade, sexo etc.);

b) função pragmática: expressar cortesia e descortesia.

Em relação à dêixis social, é importante destacar o caráter das relações que se estabelecem entre os interlocutores, ou seja, há neste facework (trabalho de imagem) um código de implícitos correspondentes às questões de autoridade, vínculo familiar, situação etc., que fazem as formas de tratamento estarem atreladas a uma escolha determinada pelo contexto em que se apresentam.

A outra função a ser considerada, a pragmática, está centrada no uso e nos procedimentos linguísticos empregados pelos interlocutores; isto é, a forma escolhida pode ter a capacidade de minimizar o que é expresso quando parecer ameaçador (ataque à imagem do interlocutor), ou para amenizar situações de negatividade, indicando aproximação ao locutor/interlocutor. 
Ainda em relação à função pragmática, Silva (2008, p. 165) aponta que "não se pode dizer que esta ou aquela forma está marcada pela cortesia, pois é a situação de uso que sinalizará que tal forma de tratamento será cortês ou descortês".

\section{VOCATIVO}

A partir do entendimento dado às formas de tratamento é que destacamos o vocativo. Inicialmente, nas suas definições no âmbito gramatical e, na sequência, o entendimento pragmático, foco do nosso estudo.

A gramática tradicional define o vocativo como um termo que mantém relação sintática com outro termo da oração. Observemos que segundo Cunha (1975, p. 167), o vocativo "serve para invocar, chamar ou nomear, com ênfase maior ou menor, uma pessoa ou coisa personificada". E, o autor nos dá o seguinte exemplo: "Ó mar anterior a nós, teus medos tinham coral e praias e arvoredos - Fernando Pessoa".

Por outro lado, Nascimento (2000, p. 282) afirma que o vocativo não é isolado do restante da oração. Apresenta e elucida tal fenômeno em:

(A) Mariana, traz o café!

(B) Mariana, é você?

No exemplo (A), sabe-se que a concordância dessa forma verbal (indicativo usado para imperativo) se dá, no português coloquial, com a $3^{a}$ pessoa do singular que não precisa estar expressa na oração. Os termos "Mariana" e o sujeito que está elíptico "você" são correferentes. Em (B), por sua vez, o sujeito está presente (você) e há correferência entre a pessoa do vocativo e do sujeito.

Além das definições acima, Melo (1978); Câmara Jr. (1981); Luft (1983); Cegalla (1985); Cunha e Cintra (1985); Bechara (1999); além de outros, consideraram apenas uma possível função pragmática desempenhada pelos vocativos, caracterizados como expressões de chamamento. Ainda, segundo Bechara (2001, p. 461), o vocativo pode "ser representado por pronome ou substantivo", conforme os exemplos dados por ele:

(C) Paula, não saias de junto de mim.

(D) Senhora, queira ter a bondade de sair cá para fora.

Ainda Moreira (2008) observa que a ordem dos constituintes na oração pode influenciar a função que o vocativo desempenha no discurso, destacando a sua posição: inicial, intermediária e final.

Também temos que considerar que o vocativo apresenta outras funções pragmáticas, como cortesia ou descortesia. Por exemplo, "a escolha de uma forma de tratamento pode constituir uma estratégia interativa com a finalidade de atenuar ou compensar ações verbais agressivas" (COUTO; KULIKOWSKI, 2011, p. 497).

Em decorrência disso, enfatizamos que o vocativo, visto sob a perspectiva do sistema linguístico, evidencia formas que indicam maior ou menor respeito, o que 
determina um signo de como o interlocutor concebe a identidade social de seu destinatário, como também o "reconhecimento da existência de normas sociais que sancionam o uso das distintas formas segundo uma série de parâmetros contextuais além da identidade dos participantes" (COUTO; KULIKOWSKI, 2011, p. 497).

Percebe-se que não é tão simples definir a forma de tratamento vocativo, mas ao ser compreendido na interação comunicativa, ele adquire uma nova dimensão, a pragmática, na qual pode-se inferir as funções de (des)cortesia.

\section{CORTESIA, DESCORTESIA E ANTICORTESIA}

A cortesia pode ser entendida como um conjunto de normas sociais que conduz a conduta do indivíduo durante a interação com outras pessoas. Ela está relacionada ao conceito de imagem, uma vez que o indivíduo utiliza determinadas estratégias para obter determinados resultados, prevenindo a própria face, e isso ocorre de maneira intencional. Segundo Haverkate (1994, p. 50-51), mostrar cortesia verbal é um tipo de ação que consiste na "seleção de determinadas estratégias convencionais", que tem a finalidade de reforçar a imagem positiva do interlocutor ou de prevenir possíveis ameaças à própria imagem.

Briz (2004, p. 71) destaca que as intervenções corteses estão convencionalizadas culturalmente, isto é, "uma cultura freqüentemente subjetiviza o uso de certos mecanismos linguísticos para mitigar, subtrair forças ilocutivas, que são assim codificadas para a expressão de cortesia naquela língua".

A partir do momento em que violamos as regras, colocando em risco a imagem do outro, temos a descortesia, que, segundo Culpeper (2005), pode ser consciente ou inconsciente. Segundo ele (2005, p. 38), "a descortesia ocorre quando: (1) o falante comunica intencionalmente o ataque à imagem, ou (2) o ouvinte percebe e / ou constrói o comportamento como intencionalmente de ataque à imagem, ou uma combinação de (1) e (2)"'2.

Para Kaul de Marlangeon (2012) cortesia e descortesia não podem ser consideradas como um par antinômico, mas como extremos de um continuum no qual, segundo a autora (2012, p. 83), "a força da cortesia-descortesia é uma propriedade permanente dos atos de fala e inerente a eles, complementar à força ilocucionária e obrigatória como esta e que se organiza num contínuo" 3 . Importante ressaltar que nem sempre o que se considera descortês em determinada situação comunicativa é de fato descortês, temos que ter em

\footnotetext{
${ }^{1}$ Do original: una cultura subjetiviza de manera frecuente el uso de ciertos mecanismos lingüísticos para mitigar, restar fuerza ilocutiva, que quedan de ese modo codificados para la expresión de la cortesía en dicha lengua (tradução nossa).

${ }^{2}$ Do original: Impoliteness comes about when: (1) the speaker communicates face-attack intentionally, or (2) the hearer perceives and/or constructs behaviour as intentionally face-attacking, or a combination of (1) and (2) (tradução nossa).

${ }^{3}$ Do original: la fuerza de cortesía-descortesía es una propiedad permanente de los actos de habla e inherente a éstos, complementaria de la fuerza ilocutoria y obligatoria como ésta y que organiza un continuo (tradução nossa).
} 
mente as relações contextuais, gerais e específicas, da interação, bem como a afinidade entre os interlocutores.

Ainda, em relação à descortesia, Kaul de Marlangeon (2012, p. 10-14) propõe três níveis, a saber:

1. A descortesia de fustigação, representativa da atitude de descortesia e de ofensa proferida pelo locutor ao interlocutor e que busca o confronto no discurso. Kaul Marlangeon (2017) a define como agressão verbal constituída em sua maioria por "comportamientos volitivos, conscientes y estratégicos", cuja finalidade, é de ferir a imagem do interlocutor como resposta a uma situação de enfrentamento ou desafio, ou como início dela.

2. Atos descorteses involuntários - as gafes. São atos descorteses não intencionais, de caráter involuntário e, segundo a autora, "a nomenclatura deste ato de fala demonstraria os parâmetros culturais que convergiriam em considerá-lo um erro ou passo em falso" (KAUL DE MARLANGEON, 2012).

3. Atos de negação deliberada de cortesia esperada pelo ouvinte e atos de silêncio opressivo. Seria o tipo de descortesia que se opera por omissão e não por ação, isto é, o ouvinte apela deliberadamente para o silêncio com o intuito de decepcionar surpreendentemente o falante que, por obra do contexto situacional e do compromisso entre os interlocutores, espera por um comportamento linguístico diametralmente oposto.

E, finalmente, a anticortesia, que, segundo Zimmermann (2005), faz menção aos insultos. Aqui os insultos são usados não para ser descortês com o interlocutor, mas, sim, para que na interação os interlocutores tenham reforçadas as condições de pertencimento a um grupo social específico. Segundo o autor, "“eu’ tem à sua disposição estratégias para influenciar a visão que o outro tem do próprio 'eu'. Ao mesmo tempo, a EU contribui com seus atos de atribuição de identidade para a construção do 'eu' do outro. Esses tipos de atos podem ser chamados de atos de identidade"4 (ZIMMERMAN, 2005, p. 268).

Quando os insultos configuram atos anticorteses, os destinatários não parecem se sentir atacados ou ofendidos quando o emissor os dirige, pelo contrário, pareceria que lhes agradava. Não há ruptura e nem conflitos na intercomunicação, esta flui naturalmente, de acordo com Zimmermann (2005, p. 249). Os insultos, desta forma utilizados, conformam uma estratégia (não é convencional e sim volitiva) de afiliação, nos termos propostos por Bravo (2004 apud BLANCO, 2015), já que supõe a pertença a um grupo especial que maneja um código linguístico diferenciado.

A partir desses aspectos teóricos, vejamos na análise do corpus como o vocativo se apresenta, uma vez que as formas de tratamento nominais e as formas apelativas convencionalizadas "podem ter um papel atenuante uma vez que mostram aproximação ao outro ou podem ter a capacidade de minimizar o expressado quando pode parecer

\footnotetext{
${ }^{4}$ Do original: El "yo" tiene a su disposición estrategias para influir en la visión que el otro tiene del propio "yo". Al mismo tiempo el YO contribuye con sus actos de atribución de identidad a la construcción del YO del otro. Este tipo de actos se pueden llamar actos identitarios (tradução nossa).
} 
ameaçador, ou para atender situações de negatividade” (BLANCO, 2015, p. 53-54).

\section{CORPUS E ANÁLISE}

Lançado em 1944, Meu destino é pecar de Nelson Rodrigues, narra a história de Leninha que se casa com Paulo, um homem que ela não ama, para evitar conflitos financeiros em sua família. Ao chegar ao local que irá morar com o esposo, Leninha tem que lidar com as lembranças da ex-mulher de Paulo, as intrigas com a sogra e a rivalidade de Paulo com o irmão Maurício, por quem ela se apaixona.

\subsection{EXEMPLO 1: VOCATIVO + FORMA PRONOMINALIZADA}

Inicialmente, vamos retirar um exemplo que expressa a forma pronominalizada do uso do vocativo.

No diálogo a seguir, temos a conversa entre mãe e filho:

— Vem cá, mamãe! Está vendo essa aqui?

- Estou.

- Que é que a senhora acha?

- Mas acho como?

- Sabe o que ela me fez?

- Que foi?

- Uma declaração de amor. (Meu destino é pecar, p. 375)

Quando o filho se dirige à mãe com o vocativo "mamãe", percebemos o seu uso com a intenção de chamar a mãe a quem o filho se refere. Em seguida, o tratamento pronominal "a senhora" dirigido à mãe demonstra a posição de papéis hierárquicos, mãe e filho, pois conforme o status que o indivíduo ocupa deve haver uma subordinação a determinado comportamento, bem como a um conjunto de regras e posturas éticas. Ou seja, a volta ao uso protocolar ("senhora"), recompõe o papel estabelecido pelos agentes na interação e pode mostrar deferência, respeito.

Quanto à função pragmática, há estrategicamente, o uso da forma carinhosa de tratamento "mamãe", que estabelece, enquanto procedimento linguístico, aproximação com a interlocutora, possivelmente, releva uma intenção de que a mãe aprove a companheira do filho.

\subsection{EXEMPLO 2: VOCATIVO + CORTESIA (AFEIÇÃO)}

No exemplo a seguir, temos mãe e filho conversando sobre apresentar o irmão para a cunhada:

- Que é isso? 
— Isso o que, meu filho? Ela adoçava a própria atitude, procurava tornar a voz menos ríspida.

- A senhora ainda não apresentou Maurício a Leninha!

- Mas ainda ia apresentar, meu filho!

- Não ia, não, senhora; não ia apresentar! A senhora apresentou todo mundo, menos ele! Parece que tem medo de alguma coisa!

- Que bobagem, meu filbo! (Meu destino épecar, p. 24)

Observamos que a mãe de Maurício procura atenuar o discurso quando utiliza o vocativo "meu filho" repetidas vezes, para amenizar o fato de ainda não ter apresentado Maurício a Leninha. "Meu filho", nesse uso reiteirado, evidencia que a mãe tenta proteger a sua própria imagem e ao mesmo tempo, manter contato na interação. Notamos que há também uma tentativa de aproximação social (mãe-filho) e menor imposição entre os papéis que exercem (respeito e proximidade, dado o convívio familiar).

\subsection{EXEMPLO 3: VOCATIVO + DESCORTESIA}

Usando o mesmo trecho do exemplo, temos o discurso entre a mãe e o filho, mas revelando descortesia:

- Não ia, não, senhora; não ia apresentar! A senhora apresentou todo mundo, menos ele! Parece que tem medo de alguma coisa!

- Que bobagem, meu filho! (Meu destino épecar, p. 24)

A marcação "senhora" (intermediária), por parte do locutor, mostra um ataque à imagem da mãe que é uma figura de respeito no meio familiar. Também revela um distanciamento social, como se fosse uma repreensão por parte do filho, constituindo uma quebra ou ameaça à hierarquia entre ambos. De fato, o vocativo "senhora" nem precisaria estar presente no enunciado, poderia ter sido elidido; contudo, se se apresenta, marca, como dissemos, o caráter de descontentamento dado pelo filho. $\mathrm{O}$ filho não utiliza o termo "mãe" para se dirigir a ela, isso mostra que de fato ele quer ser descortês quando utiliza a forma de tratamento "senhora".

\subsection{EXEMPLO 4: VOCATIVO + DESCORTESIA CONSCIENTE}

No fragmento seguinte, Dona Consuelo conversa com o filho Maurício sobre a nora Leninha:

- Ora, mamãe! Será possível?

Mas D. Consuelo não parou mais; as coisas acumuladas, as queixas do filho, os seus receios, tudo saiu nas palavras: 
- Se fosse, ainda uma mulher bonita, eu compreendia. Mas essa magricela? Ah, não, Maurício, tenha paciência! Você não pode causar uma desgraça por causa de uma mulher dessas!

- Mamãe, quem deve achar se ela é magricela ou não, se vale ou não vale a pena, sou eu. Ou é a senhora? (Meu destino é pecar, p. 66)

Poderia ter iniciado o enunciado somente com "ora" ou "mamãe". A forma como se apresenta mostra ao mesmo tempo uma decepção ("ora") e a aproximação do interlocutor ("mamãe"). Há um jogo no qual a decepção do locutor prevalece no enunciado ("será possível").

$\mathrm{Na}$ interação, a mãe tenta se autoproteger ao usar estratégias como "Mas essa magricela" e, na continuidade de seu dizer “Ah, não, Maurício, tenha paciência!", revela o ataque à imagem ao filho. $\mathrm{O}$ vocativo, aqui, tem papel relevante, pois não só nomeia $\mathrm{o}$ sujeito da situação, mas também ironiza-o com a força ilocutória “tenha paciência!".

Por sua vez, no jogo, o filho, ao usar "mamãe", tenta aproximar-se estrategicamente da interlocutora para dar sua opinião final ("Mamãe, quem deve achar se ela é magricela ou não, se vale ou não vale a pena, sou eu. Ou é a senhora?"), que é desafiante e também um ataque à imagem da mãe.

Ambos se valem da descortesia para atacar as imagens. É o tipo de descortesia denominada de fustigação, que tem como característica a ofensa proferida pelo locutor ao interlocutor e que busca o confronto no discurso, segundo Marlangeon (2012).

\subsection{EXEMPLO 5: VOCATIVO + DESCORTESIA (MENOSPREZO)}

O seguinte trecho tem como contextualização o fato de Maurício trocar o nome da amante Lena por Lídia:

— Lídia? - ele não compreendeu imediatamente, custou.

- Lídia, claro.

Maurício riu, julgou compreender tudo. Exultou: — Ah, agora percebo! Você está com ciúmes! Riu mais alto.

Lena reagiu, como se um bicho a tivesse picado: - Ciúmes de você? Eu? Está doido! Por mim, meu filho, você pode gostar de quem quiser, eu não tenho nada com isso! Mas nada!

- Sabe o que é que dizem as moças que eu namorei?

- Não me interessa! (Meu destino é pecar, p. 162)

O uso do vocativo "meu filho", proferido por Lena, revela descortesia e menosprezo em relação ao cunhado Maurício, uma vez que este ri e insulta a cunhada para provocar ira e ódio. Também, seu uso, revela uma situação irônica, pois "meu filho", na voz de Lena, cria uma situação hipotética na qual a relação mãe-filho é fantasiosa; e, pode dar a locutora uma certa superioridade hierárquica na situação apresentada.

Ao mesmo tempo, percebe-se que Lena tenta ser indiferente em relação à fala do 
cunhado, uma vez que o responde de maneira direta, encerrando a possibilidade da continuidade do discurso.

\subsection{EXEMPLO 6: VOCATIVO + DESCORTESIA (IRONIA)}

Neste contexto abaixo, a esposa declara o amor ao marido, mas a sogra sente que é falsidade:

D. Consuelo não sabia o que dizer. Achava a situação falsa, incrível, e, ainda por cima, ridícula. Fez um comentário bobo, que lhe ocorreu no momento:

- Você é tão criança, Paulo!

- Criança por que, mamãe? Não acha que eu devo estar radiante! Minha mulher confessou que me ama! (Meu destino é pecar, p. 371).

Como a mãe já tem conhecimento de toda a situação do filho com a esposa, e também do interesse de Lena pelo cunhado Maurício, ao utilizar o vocativo "Paulo" adjetivando-o como criança, percebe-se que há ironia na forma com a qual se dirigiu ao filho, que acredita, ainda, na relação dele com a esposa. Conforme Kaul de Marlangeon (2012), corresponde a uma descortesia com o objetivo de menosprezar e anular o ouvinte, ou seja, atacar a imagem do interlocutor.

Já Paulo faz uso do recurso linguístico da aproximação "mamãe", nomeando o ser que ama de forma carinhosa e estabelecendo o equilíbrio da interação.

Dos exemplos dados, constatou-se que o vocativo deixa um leque abrangente de usos na interação, seja aproximando ou distanciando os interlocutores. Ainda, dos exemplos, percebemos que não houve o uso de insultos, conforme a concepção de Zimmermann (2005), talvez pelo fato de não haver entre os interlocutores uma identificação social coesa e de pertencimento.

\section{CONSIDERAÇÕES FINAIS}

O objetivo do estudo era mostrar como as formas de tratamento consideradas prototipicamente corteses -aquelas que mantêm o equilíbrio das imagens dos interactantes na interação- poderiam ser empregadas com finalidade descortês. Em específico, a forma de tratamento "vocativo".

A partir dos conceitos mais tradicionais, pontuamos que o vocativo deveria ser entendido em uma dimensão ampla, isto é, de acordo com sua função pragmática e não somente gramatical.

Assim, o seu uso nos enunciados nos revelou características de cortesia e também de descortesia, devendo, as formas de tratamento ser compreendidas como um componente do construto social determinado e determinante da cultura na qual se inserem. 
Também ficaram exemplificadas diferentes estratégias de uso e como elas são determinadas por fatores contextuais presentes nas situações de fala, revelando usos estratégicos de cortesia ou descortesia.

\section{REFERÊNCIAS}

BECHARA, E. Moderna gramática portuguesa. $37^{\mathrm{a}} \mathrm{ed}$ rev., ampl. e atual. Rio de Janeiro: Nova Fronteira, 2009.

BLANCO, R. Atenuação pragmática e problemas de intercompreensão: um estudo intercultural entre paulistanos e cordobeses. 2015. 195 f. Dissertação (Mestrado em Letras) - Universidade de São Paulo, São Paulo, 2015. Disponível em: <http://www.teses.usp.br/teses/disponiveis/8/8145/tde-06062016-121646/ptbr.php>. Acesso em:14 jan. 2018.

BRAVO, D. Tensión entre universalidad y relatividade em las teorías de la cortesía. In: BRAVO, D; BRIZ, A. Pragmática sociocultural: estudios sobre el discurso de cortesia en español. Barcelona: Ariel, 2004.

BRIZ, A. Cortesía verbal codificada y cortesía verbal interpretada en la conversación. In: BRAVO, D.; BRIZ, A. (Eds.). Pragmática sociocultural: estudios sobre el discurso de cortesía en español. Barcelona: Ariel, 2004.

BROWN, P.; LEVINSON, S. C. Politeness. Some universals in language use. Cambridge: Cambridge University Press, 1987[1978].

BROWN, R.; GILMAN, A. The pronouns of power and solidarity. In: Style in language. Cambridge: MIT Press, 1960, p. 253-276.

COUTO, L. R.; KULIKOWSKIZ. M. El voseo argentino y el voseo chileno: diferencias sociolingüísticas y conversacionales a través de diálogos cinematográficos y textos en internet. In: COUTO, L. R.; SANTOS, C. R. (Orgs.). As formas de tratamento em português e em espanhol: variação e funções conversacionais. Niterói: Editora da Universidade Federal Fluminense, 2011, p. 497-531.

CULPEPER, Jonathan. Impoliteness: using language to cause offence. New York: Cambridge University Press, 2011.

CULPEPER, J. Impoliteness and entertainment in the television quiz show: the weakest link. Journal of Politeness Research, v. 1, p. 35-72, 2005.

CUNHA, Celso. Gramática do português contemporâneo. $2^{\mathrm{a}}$ ed. Belo Horizonte: Bernardo Álvares S.A., 1971.

HAVERKATE, H. La cortesía verbal. Madri: Gredos, 1994.

KAUL DE MARLANGEON, S. Encuadre de aspectos teóricos-metodológicos de la descortesía verbal en español. In: MORALES, J. E.; VEGA, G. H. (Orgs.). Miradas multidisciplinares a los fenómenos de cortesia y desortesía en el mundo bispânico. Barranquilia, Estocolmo: Cadis, Programa Edice, 2012, p. 76-106.

KAUL DE MARLANGEON, S. Tipos de descortesía verbal y emociones en contextos de cultura hispanohablante. In: BRAVO, D. Pragmática sociocultural/sociocultural pragmatics. Revista Internacional sobre Lingüistica del Español, Edice, 2017. Disponível em: $<$ https://www.degruyter.com/view/j/soprag.ahead-of-print/soprag-2017- 


\section{Revista

0001/www.degruyter.com/view/j/soprag.ahead-of-print/soprag-2017-0001/soprag2017-0001.xml>. Acesso em: 21 nov. 2017.

MOREIRA, J. C. O vocativo e a interface sintaxe-pragmática no português brasileiro. 2013. $151 \mathrm{f}$. Tese de Doutorado em Estudos Linguísticos. Faculdade de Letras da Universidade Federal de Minas Gerais, Belo Horizonte, 2013.

MOREIRA, J. C. O vocativo no português brasileiro: uma unidade à parte?. Estudos Linguísticos e Literários, n. 57, Salvador, p. 319-340, jul-dez./2017.

NASCIMENTO, A. F. Análise prosódica do vocativo na fala de criança: uma abordagem fonética. 2000. 75 f. Dissertação de Mestrado em Estudos Linguísticos. Faculdade de Letras da Universidade Federal de Minas Gerais, Belo Horizonte, 2000.

PRETI, D. Papéis sociais e formas de tratamento em $A$ ilustre casa de Ramires, de Eça de Queiroz. In: PRETI, Dino (Org.). Estudos de lingua oral e escrita. Rio de Janeiro: Lucerna, 2004.

RODRIGUES, N. Meu destino é pecar. Rio de Janeiro: Nova Fronteira, 2013.

SILVA, L. A. Cortesia e formas de tratamento. In: PRETI, D. Cortesia verbal. São Paulo: Humanitas, 2008, p. 157-191.

ZIMMERMANN, K. Construcción de la identidad y anticortesía verbal. Estudio de conversaciones entre jóvenes masculinos. In: BRAVO, Diana (Ed.). Estudios de la (des)cortesiaenespañol: categorias conceptuales y aplicaciones a corpora orales y escritos. Buenos Aires: Dunken, 2005, p. 245-271.

Recebido em: 28/02/2019

Aprovado em: 07/06/2019

Publicado em: 01/12/2019 